\title{
ボンドグラフ法による空気圧システムモデル化に関する一提案*
}

\author{
桜井康 雄 ${ }^{*}$, 田中和 博***, 中田 毅****
}

\section{Proposal for Modelling of a Pneumatic System by Bond Graph Method}

\author{
Yasuo SAKURAI, Kazuhiro TANAKA, Takeshi NAKADA
}

In modeling a pneumatic system with fluid-flow and thermal fields by bond graph method, two kinds of bonds, multi-port $\mathrm{C}$ and multi-port $\mathrm{R}$ elements have been used. Hence, the resulting bond graph model becomes complicated. To overcome this problem, one of the authors had proposed a new bond graph method by introducing a new definition about effort and flow. However, the simulation based on the bond graph model derived by the proposed method seems to be difficult since the denominators of effort and flow include variables such as density and temperature of air, and coefficient of TF-element is variable. Therefore, it seems to be difficult to use the proposed method in the simulation of a practical pneumatic system. Hence, in this study, another bond graph method for modeling a pneumatic system is proposed. In modeling of fluid flow fields, pseudo bond-graph is employed. In the proposed method, a kind of bond, 1 -port $\mathrm{C}$ element, 1 -port $\mathrm{R}$ element and TF-element with a constant coefficient are used for modeling of such a system. To confirm the validity of the proposed method, simulation for a simple pneumatic system is carried out. By comparing the simulated results with the experimental ones, the validity of the proposed bond graph method is clarified.

Key words : Bond graph method, Pneumatics, Modeling, Simulation, Dynamic characteristics

\section{1. 緒言}

油空圧システムの設計・改良は, 設計者の経験に依ると ころが大きい．このようなシステムの設計・改良を効率化 し系統的に進めるためには，コンピュータ・シミュレー ションにより，システムの動特性を前もって把握すること が望まれる，その際に用いられる手法の一つが，エネルギ の流れに沿ってシステムのモデルを作成するボンドグラフ 法1),2)である.

空気圧システムは, 圧縮性流体系と熱系を含み動的な温 度変化を考慮しなければならず, 空気の状態変化を一定の ポリトロープ指数で仮定することが困難である ${ }^{3)}$.このよ うなシステムをモデル化する場合, ボンドグラフ法では, 真ボンドグラフあるいは擬似ボンドグラフが用いられる (1), 2) $^{2}$.

真あるいは擬似ボンドグラフを用い圧縮性流体系と熱系 を含む空気圧システムのモデル化を行った場合, 流体系の エネルギの流れを表すボンドと熱系のエネルギの流れを表

\footnotetext{
*平成28年 4 月 18 日 原稿受付

**足利工業大学工学部創生工学科

(所在地 ₹326-8558 栃木県足利市大前町268-1)

(E-mail : ysakurai@ashitech.ac.jp)

***九州工業大学情報工学部機械情報工学科

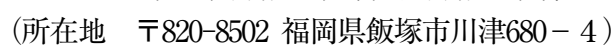

****東京電機大学情報環境学部情報環境学科

(所在地 T270-1382 千葉県印西市武西学園台 2-1200)
}

す 2 種類のボンドが必要になる.ささらに，熱系のエネルギ の流れを考慮しないボンドグラフモデルでは使用しない複 数のポートを有するマルチポートC素子およびマルチポー 卜R素子が用いられる。このマルチポートCあるいはマル チポートR素子を用いた場合，エネルギの流れの分岐ある いは合流を判断するのが困難なモデルになってしまう。こ れらのことにより, 真あるいは擬似ボンドグラフを用いた 空気圧システムのボンドグラフモデルは複雑なものとなっ てしまう.

筆者らが開発した油圧回路設計・動特性解析用シミュ

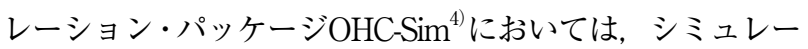
ションにはBGSP ${ }^{5}$ を改良したBGSP for OHC-Simを用いてい る. OHC-Simの用途を広げ有効活用を図るためには, 空気 圧システムの動特性のシミュレートを可能とすることが必 要である. しかしながら, OHC-Simにおいて空気圧システ ムの動特性のシミュレーションを可能とするためには, 空 気圧システムのモデル化に際しては，1種類のボンド， 1 ポートC素子および 1 ポートR素子を用いたモデル化手法 が必要となる，一方，BGSPを改良した場合においては， 従来の手法では流体系と熱系のボンドが混在するため, データベース内の空気圧素子の数学モデルが複雑になり, データベースの作成および維持管理が困難になることが懸 念される.

このような観点から, 筆者らの一人は, 圧縮性流体系と 熱系のエフォートとフローに新しい定義を導入し, 空気圧 
システムの新しいボンドグラフモデル化手法を提案した6). ここで提案した手法では, 基本変数の積が動力となる真ボ ンドグラフを用いており，モデル化には 1 ポートC素子お よび 1 ポートR素子を使う。そのため, 得られたボンドグ ラフモデルからエネルギの流れを容易に理解することがで き，この手法を用いれば，OHC-Simに空気圧システムのモ デルを取り込むことが可能となる. しかしながら，エ フォートとフローに新しい定義を導入したことにより，空 気が有する動力をピストンにより機械的な動力に変換する 場合, 可変変換比を持つトランスフォーマが必要となる. また，新たに定義した圧縮性流体系のエフォートの分母に は空気の密度が, 熱系のフローの分母には空気の温度を用 いている，そのため，シミュレートするシステムが複雑と なった場合, 数值計算上の誤差によりシミュレーションの 安定性に問題が生じることが懸念される.

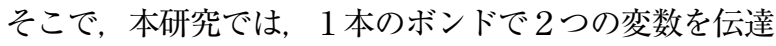
することができるというボンドグラフ法の長所の一つと信 号を伝達するアクティブボンドを活用し，さらに熱系のエ ネルギの流れを陽には表現しないこととしたモデル化手法 を提案する．ここで提案する手法では，圧縮性流体系には エフォートを絶対圧力，フローは質量流量とした擬似ボン ドグラフを用いる．また，機械系にはエフォートを力，フ ローを速度とする真ボンドグラフを用いる。 ここで提案す る手法は，流体系のボンドには擬似ボンドグラフを用いる ものの，熱系と流体系の 2 種類のボンドを必要とせず， マ ルチポートC素子およびマルチポートR素子を使用しない という特長を有する. さらに, 空気が有する動力をピスト ンにより機械的な動力に変換する場合，可変変換比を持つ トランスフォーマを必要としない。ここで提案したボンド グラフ法の妥当性を検討するため, 簡単な空気圧システム を対象としてコンピュータ・シミュレーションを行い，実 験結果と比較検討する。 なお，シミュレーションに際して は， 1 種類のボンド， 1 ポートCおよび 1 ポートR素子の みに対応しているBGSPをシミュレーションプログラムと して用い, パソコンの画面上にボンドグラフモデルの編集 機能を持たせた市販のボンドグラフ用ソフトMr.Bond ${ }^{7)}$ を 使用した。

\section{2. 主な記号}

$A$ : ピストンの断面積

$A_{e}$ : 絞り（弁）の有効断面積

$A_{S}$ : シリンダあるいは容器の表面積

$C_{P}:$ 定圧比熱

$C_{V}$ : 定容比熱

$e:$ エ エフォート

$F:$ 力

$f:$ フロー

$\dot{H}$ : エンタルピ流束 $h$ ：熱伝達率

$M$ : 空気の質量

$\dot{m}$ : 質量流量

$P$ : 空間平均絶対圧力

$\dot{Q}$ : 熱流束

$q$ : デイスプレースメント

$R$ : ガス定数

$T$ ：空間平均絶対温度

$t$ : 時間

$U$ : 内部エネルギ

$V$ : 容積

$v \quad:$ ピストン速度

$x$ : ピストン変位

$k$ : 比熱比

$\rho$ : 空気の密度

添字

0 ：初期状態

$S$ : 周囲の大気

in : 入口側

out : 出口側

\section{3. 提案するボンドグラフ法と空気圧基本素子のモデル}

ここでは，空気圧システムの基本要素である空気圧シリ ンダの容積室および絞りのボンドグラフモデルの導出を行 う．空気を理想流体とし，圧縮性流体系のボンドグラフに おいては擬似ボンドグラフを用いる。 すなわち，エフォー トには絶対圧力，フローには質量流量を使用する。また， 機械系のボンドグラフには，エフォートが力，フローが速 度である真ボンドグラフを用いる．本論文で使用するボン ドグラフの基本変数についてまとめたものをTable 1に示す.

\section{1 空気圧シリンダ容積室のボンドグラフモデル}

ここではより一般的なモデルを導出するため, Fig. 1に示 した通り，空気の入口および出口とピストンを有する空気圧 シリンダ容積室を考える. ここに熱力学の第一法則を用いる と以下の式を得る。

$$
\dot{Q}_{S}+\dot{H}_{\text {in }}-\dot{H}_{\text {out }}=\frac{d U}{d t}+P \frac{d V}{d t}
$$

熱エネルギは壁に蓄積されないと仮定すると，壁から流 入する熱流束は以下の式で表すことができる.

Table 1 Variables of proposed bond graph method

\begin{tabular}{|c|c|c|}
\hline General & Compressible Fluid-flow & Mechanics \\
\hline$e$ & $P$ & $F$ \\
\hline$f$ & $\dot{m}$ & $v$ \\
\hline$q$ & $M$ & $x$ \\
\hline
\end{tabular}




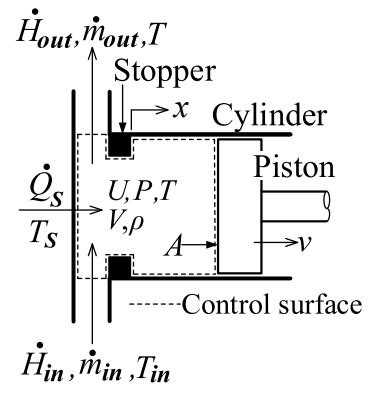

Fig. 1 Piston chamber with two port

$$
\dot{Q}_{S}=h A_{S}\left(T_{S}-T\right)
$$

ここで， $T_{S}$ は周囲の大気の温度である. 式(2)中の $A_{S}$ はピ ストンが動くことにより変化する，すなわち，外部からの 熱の流入に関係する表面積 $A_{S}$ はピストン変位 $x$ の関数である.

また,コントロールボリューム内の空気の内部エネルギ およびコントロールボリュームに流入あるいは流出するエ ンタルピ流束はそれぞれ式(3)から(5)で表すことができる.

$$
\begin{aligned}
& U=C_{V} \rho V T \\
& \dot{H}_{\text {in }}=C_{P} \dot{m}_{\text {in }} T_{\text {in }} \\
& \dot{H}_{\text {out }}=C_{P} \dot{m}_{\text {out }} T
\end{aligned}
$$

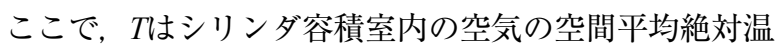
度である。

式(1)に式(2)から式(5)を代入して整理すると式(6)を得る.

$$
\begin{aligned}
C_{V} \frac{d(\rho V T)}{d t}= & C_{P} \dot{m}_{\text {in }} T_{\text {in }}-C_{P} \dot{m}_{\text {out }} T \\
& +h A_{S}\left(T_{S}-T\right)-P \frac{d V}{d t}
\end{aligned}
$$

理想気体の状態式, 定圧比熱と定容比熱の関係, 比熱比 と気体定数および定容比熱の関係を表した式(7)から式(9)を 式(6)に用いると式(10)を得る.

$$
\begin{aligned}
& \rho=\frac{P}{R T} \\
& \frac{C_{P}}{C_{V}}=\kappa \\
& \kappa=\frac{R}{C_{V}}+1 \\
& \frac{d P}{d t}=\frac{\kappa}{V}\left\{R\left(\dot{m}_{\text {in }} T_{\text {in }}-\dot{m}_{\text {out }} T\right)\right. \\
& \left.\quad+\frac{R}{C_{P}} h A_{S}\left(T_{S}-T\right)-P \frac{d V}{d t}\right\}
\end{aligned}
$$

式(10)において容積 $V$ は初期容積 $V_{0}$, ピストン断面積 $A$, ピ ストン変位 $x$ り以下の式で表すことができる.

$$
V=V_{0}+A x
$$

式(10)中の $d V / d t$ はピストン断面積 $A$, ピストン速度 $v$ 用い 以下の式で表すことができる.

$$
\frac{d V}{d t}=A v
$$

式(11)および式(12)を式(10)に代入すると式(13)を得る.

$$
\begin{aligned}
\frac{d P}{d t}= & \frac{\kappa}{V_{0}+A x}\left\{R\left(\dot{m}_{\text {in }} T_{\text {in }}-\dot{m}_{\text {out }} T\right)\right. \\
& \left.+\frac{R}{C_{P}} h A_{S}\left(T_{S}-T\right)-P A v\right\}
\end{aligned}
$$

式(13)を時間積分すると式(14)を得る.

$$
\begin{aligned}
P= & \frac{\kappa}{V_{0}+A x_{t-1}} \int R\left\{\left(T_{\text {in }}\right)_{t-1} \dot{m}_{\text {in }}-R T_{t-1} \dot{m}_{\text {out }}\right. \\
& \left.-A P_{t-1} v+\frac{R}{C_{P}} h\left(A_{S}\right)_{t-1}\left(T_{S}-T_{t-1}\right)\right\} d t
\end{aligned}
$$

ただし，この式は，ボンドグラフ法では得られたボンド グラフモデルより状態方程式を導出し数值積分によりある 時間刻みで物理量を求めることを考慮に入れた式であり, 式中の添え字 $t-1$ は前の時刻の計算で既にその值が求めら れているものを近似的に用いたことを意味する. 時間積分 の時間刻みが十分小さい場合, この近似により大きな誤差 は生じないと考えられるものの保証されたものではない. そこで, シミュレーションに際しては数值積分の時間刻み を変化させこの式の収束性を確認する必要がある.なお, このような近似を行った結果, この式よりエフォートであ る圧力はフローである質量流量と速度の積分值の関数にな

り，C素子で表現できる.

一方, 式(15)に示した通り, 容積室内の温度 $T$ は容積室内 の空気の質量 $M$, 容器の体積および気体の状態式より求め ることができる.

$$
\rho=\frac{M}{V_{0}+A x} \quad T=\frac{P}{\rho R}
$$

式(14)および式(15)に基づきFig. 1に示した空気の入口およ び出口とピストンを有する空気圧シリンダ容積室のボンド グラフモデルはFig. 20ようになる. この図よりFig. 1に 示した容積室のボンドグラフモデルは 2 つの素子, 5 つ のSF素子, 1つのSE素子で表されるものの, これらのC素 子には通常のボンドグラフ法で用いられる 1 ポート素子の みが使われている. なお, この図で $\mathrm{C}_{1}$ 素子は単なる積分器 として使用されており，ここで式(14)の計算を行っている.

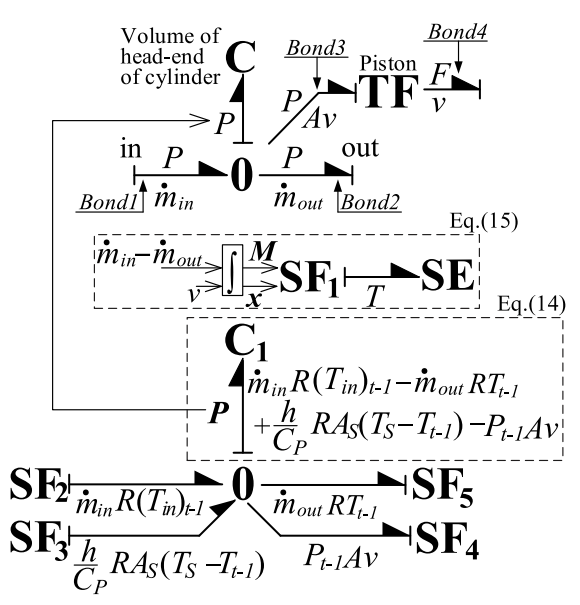

Fig. 2 Bond graph model for piston chamber with two port 


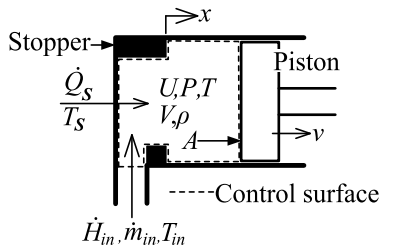

(a)Head-end chamber of cylinder

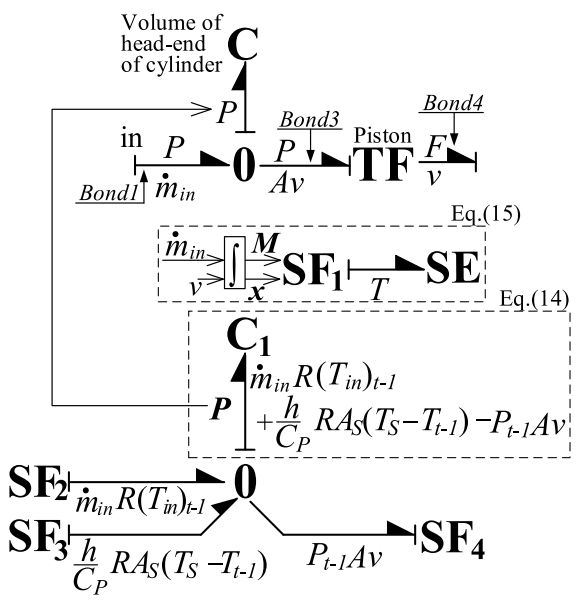

(b)Bond graph model

Fig. 3 Bond graph model for head-end chamber

TFはピストンのヘッド側の受圧面であり, その変換係数 はピストンの受圧面積 $A$ である. 図中で両矢印（開矢印） のボンドは単に信号を伝えるアクティブボンドである.

Fig. 2に示したボンドグラフモデルを用いると, 空気圧 シリンダヘッド側，ロッド側あるいは管路の容積効果のみ を考虑したボンドグラフモデルを簡単に導くことができる. Fig. 3(a)に示した空気圧シリンダヘッド側への流入のモデ ルを導く場合は, Fig. 2中のボンド 2 および素子SF5を削 除すれば良い。得られたモデルをFig. 3(b)に示す． Fig. 4 (a)空気圧シリンダロッド側からの流出のモデルを導く場 合は, Fig. 2中のボンド 1 および素子SF2を削除するとと もに, ピストンから受ける動力の方向を正とするために TF素子の矢印の向きを変えれば良い，その結果として得 られたモデルをFig. 4(b)に示す. Fig. 5(a)に示した空気圧管 路の容積効果のみを考慮したモデルを導く場合は, ボンド 3 ，TF素子，ボンド 4 および素子SF4を削除する，得られ たモデルをFig. 5(b)に示す.

\section{2 絞りのボンドグラフモデル}

Fig. 6(a)に示した空気圧システムの絞り要素において, そこを通過する質量流量は一般的に式(16)拉よび(17)で与えら れる。

$$
\begin{aligned}
& 0 \leqq \frac{P_{2}}{P_{1}}<0.528 \\
& \dot{m}=A_{e} P_{1} \sqrt{\frac{\kappa}{R T_{1}}\left\{\left(\frac{2}{\kappa+1}\right)^{\frac{\kappa+1}{\kappa-1}}\right\}}
\end{aligned}
$$

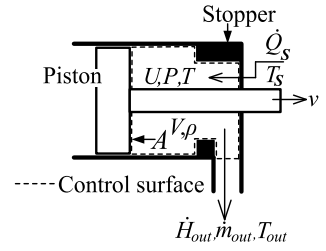

(a)Rod-end chamber of cylinder

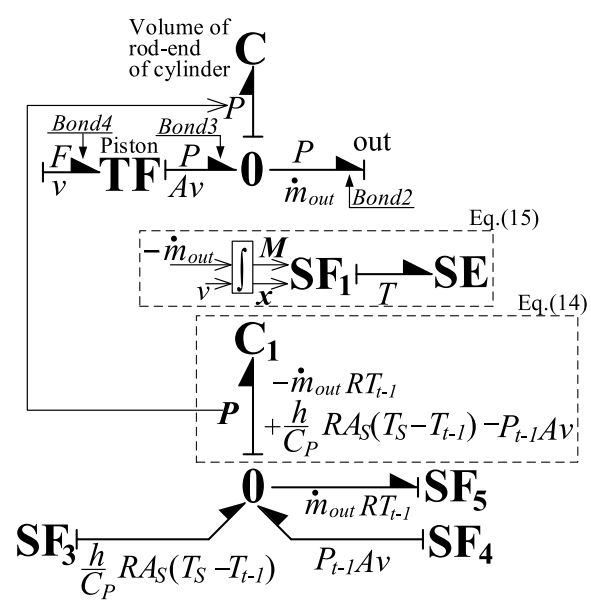

(b)Bond graph model

Fig. 4 Bond graph model for rod-end chamber

$$
\dot{H}_{\text {in }}, \dot{m}_{\text {in }}, T_{i n} \oslash \underset{V, \rho}{U, P, T} \dot{H}_{\text {Out }} \dot{m}_{\text {out }}, T_{\text {out }}
$$

(a)Pipe volume

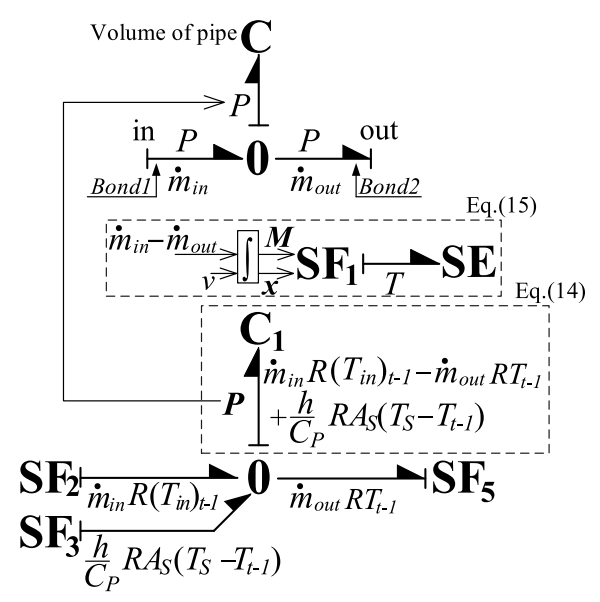

(b)Bond graph model

Fig. 5 Bond graph model for pipe volume

$$
0.528 \leqq \frac{P_{2}}{P_{1}} \leqq 1
$$

$$
\left.\dot{m}=A_{e} P_{1} \sqrt{\frac{2 \kappa}{\kappa-1} \frac{1}{R T_{1}}\left\{\left(\frac{P_{2}}{P_{1}}\right)^{\frac{2}{\kappa}}-\left(\frac{P_{2}}{P_{1}}\right)^{\frac{\kappa+1}{\kappa}}\right.}\right\}
$$

これらの式より，フローである質量流量はエフォートで ある絶対圧力の関数となっており，また，絞りを通過する 質量流量は絞り入口㧍よび出口で等しいことより, 絞りの 


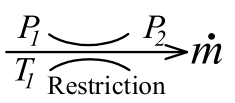

(a)Restriction

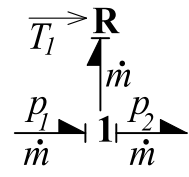

(b)Bond graph model
Fig. 6 Bond-graph model for restriction

ボンドグラフモデルは 1 ポート R 素子と 1 接点を用いて Fig. 6(b)のように表すことができることがわかる. なお, 上流側の空気の温度 $T_{1}$ はアクティブボンドにより素子に入 力する。

\section{4. シミュレーション}

本論文で提案したボンドグラフモデルの妥当性を調べる ために, Fig. 7に示すような簡単な空気圧システムのシミュ レーションを行った. 一定の容量 $V$ もつ容器に充填され ている圧縮空気が弁を通って大気中に放出され，熱流束が 容器の周囲の大気から容器内に流れ込む場合を対象とした。

Fig. 8にそのシステムのボンドグラフモデルを示す. 容 器内の温度と圧力の変化および容器の周囲の大気から容器 内への熱伝達はFig. 2 においてボンド 1 , ボンド 3 , TF素 子，ボンド 4, 素子SF2およびSF4を削除することにより モデル化できる. 弁の絞りはFig. 6に示したボンドグラフ モデルで表すことができる. 大気の圧力 $P_{S}$, 密度 $\rho_{\mathrm{S}}$ および 温度 $T_{S}$ は一定であると考えられるので，大気はSE素子で表 現することができる. Fig. 8に示した通り，ここで提案し た手法を用いたシステムのボンドグラフモデルには 1 種類 のボンド， 1 ポートCおよび 1 ポートR素子しか用いられ ていない.そのため, シミュレーションに際しては, Mr.

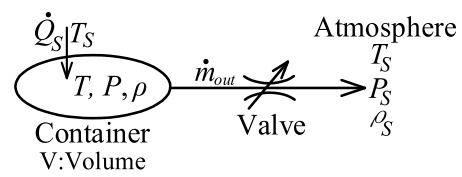

Fig. 7 Simple pneumatic system
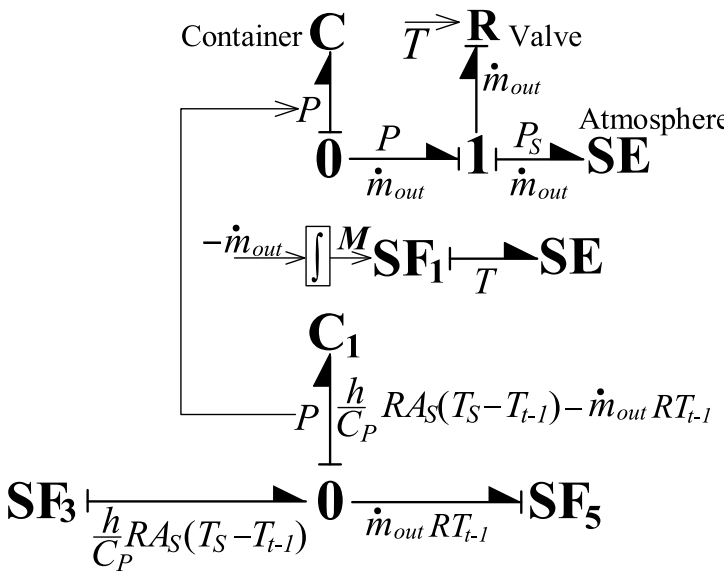

Fig. 8 Bond graph model for simple pneumatic system
Table 2 Parameters for simulation

\begin{tabular}{|c|c|c|c|}
\hline$A_{S}$ & $3.670 \times 10^{-2} \mathrm{~m}^{2}$ & $T_{0}$ & $293.16 \mathrm{~K}\left(20^{\circ} \mathrm{C}\right)$ \\
$A_{e}$ & $1.2 \times 10^{-6} \mathrm{~m}^{2}$ & $T_{S}$ & $292.16 \mathrm{~K}\left(19^{\circ} \mathrm{C}\right)$ \\
$P_{0}$ & $4.0 \times 10^{5} \mathrm{~Pa}$ & $V$ & $4.2 \times 10^{-4} \mathrm{~m}^{3}$ \\
$P_{S}$ & $1.013 \times 10^{5} \mathrm{~Pa}$ & $h$ & $10.7 \mathrm{~W} /\left(\mathrm{m}^{2} \cdot \mathrm{K}\right)$ \\
$R$ & $287.06 \mathrm{~J} /(\mathrm{kg} \cdot \mathrm{K})$ & $\kappa$ & 1.4 \\
\hline
\end{tabular}

Bondを使用した. このシミュレーションで使用したパラ メータをTable 2 に示す ${ }^{8)}$. ここで， $P_{0}$ および $T_{0}$ はそれぞれ 容器内の空気の圧力および温度の初期值である.

前述した通り, 提案したモデルでシミュレーションを行 う場合，数值積分の時間刻み $\Delta t$ を変化させて式(14)に関する 収束性を確認する必要がある。 $\Delta t$ を変化させて容器内の圧 力のシミュレーションを行った結果をFig. 9に示す.こ の図で $\Delta e_{p}$ は $\Delta t$ を $10^{-3} \mathrm{~s}$ とした場合に得られたシミュレー ション結果との差である. また, 図中の表はこの差が最大 となったときのシミュレーション結果を示す。この図より， $\Delta t$ を $10^{-6} \mathrm{~s} よ り$ 小さすれば $\Delta e_{p}$ に変化はなくなりシミュ レーション結果が収束していることがわかる. よって，こ こでは $\Delta t$ t $10^{-6} \mathrm{~S}$ してシミュレーションを行う.

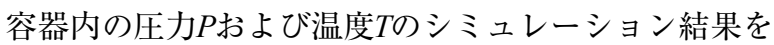
Fig. 10に示す。この図で実線はシミュレーション結果を， 破線は張らが行った実験結果 ${ }^{8) \sim 10)}$ をそれぞれ表す。この実 験では容器内に圧力および温度センサを挿入し圧力および 温度計測が行われた。 なお, 温度計測は熱電対の接点を容 器の中心部に配置することにより行われた. ここで示した 実験結果は張らが行った 5 回の実験結果を平均したもので ある。

Fig. 10のシミュレーション結果から, 容器内の圧力 $P$ は計算開始後約 2 秒間減少し, その後, $P$ は $P_{S}$ に近づい ていることがわかる。，一方，容器内の温度 $T$ は計算開始 後約 2 秒間減少し, その後, 容器周囲の大気からの熱伝 達の影響のため増加し始め, $T_{S} に$ 近づいていることがわ かる.

圧力については容器内でほぼ一様であると考えられる. 本論文で提案するモデルを使ったシミュレーションで求め た平均圧力と比較検討すると, シミュレーション結果は実 験結果を精度良くシミュレートしている．温度については 下降過程から上昇過程の前半部まではシミュレーション結

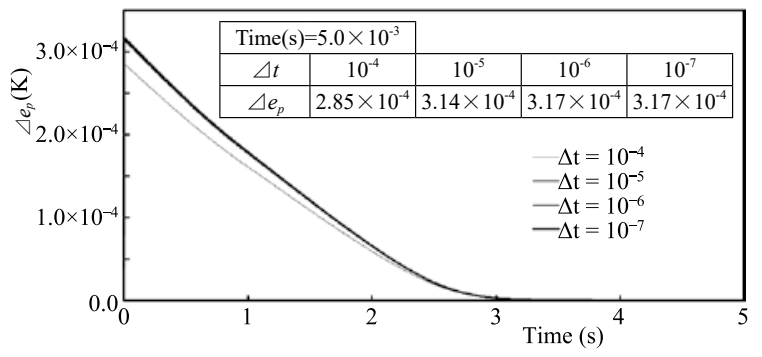

Fig. 9 Convergence property for Eq. (14) 


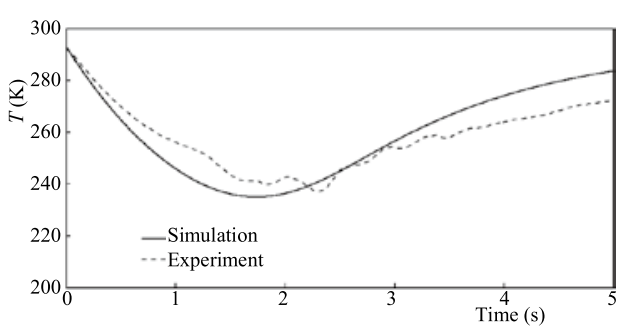

(a)Temperature in the container

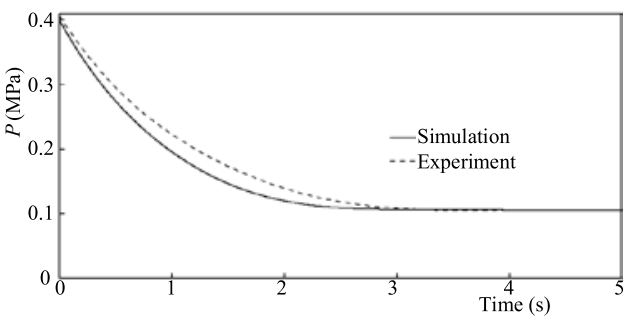

(b)Pressure in the container

Fig. 10 Comparison of simulated and experimental results

果は実験結果を良好にシミュレートしている。しかしなが ら, 上昇過程の後半部ではシミュレーション結果は実験結

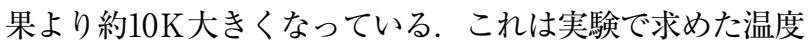
が容器の中心部の温度であり, 容器周囲から入る熱の伝わ りの遅れの影響によるものであると考えられる. よって, 今後の課題として, ストップ法 ${ }^{11)} に よ り$ 求めた容器内の平 均温度と本シミュレーションで得られた結果の比較検討に より本シミュレーションの精度について検討することが必 要である. よって, 本論文で提案した手法を用いた空気圧 システムのモデルによるシミュレートは可能であると考え られる.

ここで提案したボンドグラフを用いれば，OHC-Simや Mr. Bondのように, シミュレーションプログラムとしてBGSPを 利用しているソフトを用いて空気圧システムの動的な温度 変化のシミュレーションが可能となる.

\section{5. 結言}

本研究では, 1 本のボンドで $2 つ の$ 変数を伝達すること ができるというボンドグラフ法の長所の一つと信号を伝達 するアクティブボンドを活用しさらに熱系のエネルギの流 れを陽には表現しないこととしたモデル化手法を提案した. この手法を用いることにより, 空気圧シリンダの容積室の ような容量要素では，2つのC素子，複数のSF素子および とSE素子が必要になるものの, 圧縮性流体系と熱系を含み 動的な温度变化を考慮しなければならない空気圧システム であっても，1種類のボンド, 1 ポートC素子および 1 ポー トR素子のみでボンドグラフモデル化が可能となった.さ らに，ここで提案した手法の妥当性を調べるため簡単な空 気圧システムを例に取りシミュレーションを行い, 実験結 果と比較検討した. その結果, 得られたシミュレーション 結果は実験結果を良好にシミュレートしており，ここで提
案した手法の妥当が示された。 なお，ここで提案した手法 を用いると，1 ポートC素子および 1 ポートR素子のみで システムのボンドグラフ表現が可能となるため, シミュ レーションに際しては, シミュレーションプログラムとし てBGSPを利用しているソフトを用いて, 空気圧システム の動的な温度変化のシミュレーションが可能となる.

今後の課題は, 空気圧システムをボンドグラフ法でシ ミュレートする手法は文献 6 および文献12においても示さ れている，そこで, 本論文で提案した手法とこれらの手法 によるシミュレーション結果についての比較検討であると 考えている. また, 温度のシミュレーション結果について は，ストップ法を用いた計測結果との比較も必要である.

\section{謝 辞}

本研究にご協力いただいた当時足利工業大学大学院生羽 石祥崇氏ならびに本研究にご支援賜ったSMC株式会社に感 謝の意を表する.

\section{参 考 文 献}

1 ) Rosenberg, R.C. and Karnopp, D.C. : Introduction to Physical System Dynamics, p. 244-257, McGraw-Hill (1983)

2 ) Thoma, J. : Simulation by Bondgraphs, p. 123-132, Springer-Verlag (1990)

3 ）香川利春 : 空気圧抵抗容量系の動特性における熱伝達 の考察, 油圧と空気圧, Vol. 12, No. 3, p. 209-212 (1981)

4 ）例えば, 桜井康雄, 田中和博, 幸田武久, 中田毅 : 油 圧回路設計・動特性解析用シミュレーション・パッ ケージOHC-Simの改良, 日本油空圧学会論文集, Vol. 31, No. 6, p. 164-169 (2000)

5 ) Kohda,T., Nakada,T., Kimura,Y. and Mitsuoka,T : Simulation of Bond Graphs with Nonlinear Elements by Symbolic Manipulation, Bulletin of Mechanical Engineering Laboratory, 49 (1988)

6 ）桜井康雄, 高橋浩爾, 池尾茂 : 空気圧システムの新し いボンドグラフ表現，日本油空圧学会論文集，Vol. 30, No. 7, p. 171-176 (1999)

7 ）山本耕治：シミュレーション活用技術 油圧回路設計/ 解析システム Mr. Bondの活用事例, 油空圧技術, Vol. 48, No. 9, p. 19-23 (2009)

8 ) Zhang,H. : 空気圧システム中における結露に関する研 究, 上智大学博士論文, p. 7-33 (1995)

9 ) 張護平, 池尾茂, 高橋浩爾, 桜井康雄 : 空気圧システ 厶中における結露に関する研究（第 1 報 均一凝縮理 論による解析), 油空と空気圧, Vol. 26, No. 1, p. 93-99 (1995)

10）張護平, 池尾茂, 高橋浩爾, 桜井康雄 : 空気圧システ ム中における結露に関する研究 (第 2 報 実験), 油圧 
と空気圧，Vol. 26， No. 1， p. 93-99（1995）

11）香川利春，蔡茂林：圧縮性流体の計測と制御一空気圧 解析入門一, p. 81-82, 日本工業出版 (2010)
12）張護平：ボンドグラフ法による空気圧システムのシ ミュレーション, 油圧と空気圧, Vol. 27, No. 4, p. 92-97 (1996) 